\title{
Saponin: Role in Animal system
}

\author{
T K Das $^{1 *}$, D Banerjee ${ }^{1}$, D Chakraborty ${ }^{2}$, M C Pakhira ${ }^{3}$, B Shrivastava ${ }^{4}$ and R C Kuhad ${ }^{4}$
}

1. National Dairy Research Institute, Karnal-132001, India; 2. Assistant Professor, Division of Animal Genetics and Breeding, SKUAST-J; 3. West Bengal University of Animal and Fishery Sciences, 37 Kshudiram Bose Sarani, Kolkata-700 037, India; 4. Lignocellulose Biotechnology Laboratory, Department of Microbiology, University of Delhi South Campus, New Delhi-110021, India

* Corresponding author email: tapanndri@gmail.com

Received: 02-10-2011, Accepted: 15-11-2011, Published Online: 04-01-2012 doi: 10.5455/vetworld.2012.248-254

\begin{abstract}
Saponins are common in a large number of plants and plant products. It is having important role in human and animal nutrition. Saponins have biological role as membrane-permeabilising, immunostimulant and hypocholesterolaemic properties and it has found to have significant affect growth and feed intake in animals. These compounds have been observed to kill protozoans, to impair the protein digestion and the uptake of vitamins and minerals in the gut and to act as hypoglycemic agent. These compounds thus affect animals in both positive and negative ways.

Keywords: Growth, Plants, Protozoa, Saponin
\end{abstract}

\section{To cite this article :}

Das TK, Banerjee D, Chakraborty D, Pakhira MC, Shrivastava B and Kuhad RC (2012) Saponin: Role in Animal system, Vet. World. 5(4):248-254, doi: 10.5455/vetworld.2012.248-254

\section{Introduction}

The word 'saponin' is derived from the Latin letters 'sapo' means soap and traditionally saponincontaining plants have been utilized for washing. The saponins are naturally occurring surface-active glycosides. They are mainly produced by plants (Alfalfa, Soyabean, Lucerne, Berseem, Yucca, Mahua, Guar etc.), but also by lower marine animals (sea cucumbers, starfish etc.) and some rhizo bacteria (Yoshiki et al., 1998). They derive their name from their ability to form stable, soap-like foams in aqueous solutions. This easily observable character has attracted human interest from ancient times. Saponins consist of a sugar moiety usually containing glucose, galactose, glucuronic acid, xylose, rhamnose or methylpentose, glycosidically linked to a hydrophobic aglycone (sapogenin) which may be triterpenoid or steroid in nature. The aglycone may contain one or more unsaturated $\mathrm{C}-\mathrm{C}$ bonds. The oligosaccharide chain is normally attached at the $\mathrm{C} 3$ position (monodesmosidic), but many saponins have an additional sugar moiety at the $\mathrm{C} 26$ or $\mathrm{C} 28$ position (bidesmosidic). The great complexity of saponin structure arises from the variability of the aglycone structure, the nature of the side chains and the position of attachment of these moieties on the aglycone.

\section{Chemical Structure}

Chemically, saponins are high-molecular-weight glycosides in which sugars (1-8 residues) are linked to a triterpene or steroidal aglycone moiety (Hostettmann and Marston, 1995). Saponins possess a variety of glycosyl groups covalently bound to the $\mathrm{C} 3$ position but some saponin contain two sugar chains attached at the $\mathrm{C} 3$ and $\mathrm{C} 17$ (via C28) position (Vincken et al., 2007). A large number of saponins could be possible depending upon the modifications of the ring structure of aglycone moieties and number of sugars added to it, and in turn producing different biological properties. Saponin glycosides are divided into 2 types based on the chemical structure of their aglycones (sapogenins). Saponins on hydrolysis yield an aglycone known as "sapogenin".

$$
\begin{gathered}
\mathrm{SAPONIN}=\underset{\text { glycone }}{\mathrm{SUGAR}}+\underset{\text { aglycone }}{\mathrm{SAPOGENIN}} \\
\text { glycone }
\end{gathered}
$$

The so-called neutral saponins are derivatives of steroids with spiroketal side chains. The acid saponins possess triterpenoid structures.

The main pathway leading to both types of sapogenins is similar and involves the head-to-tail coupling of acetate units. However, a branch occurs, 

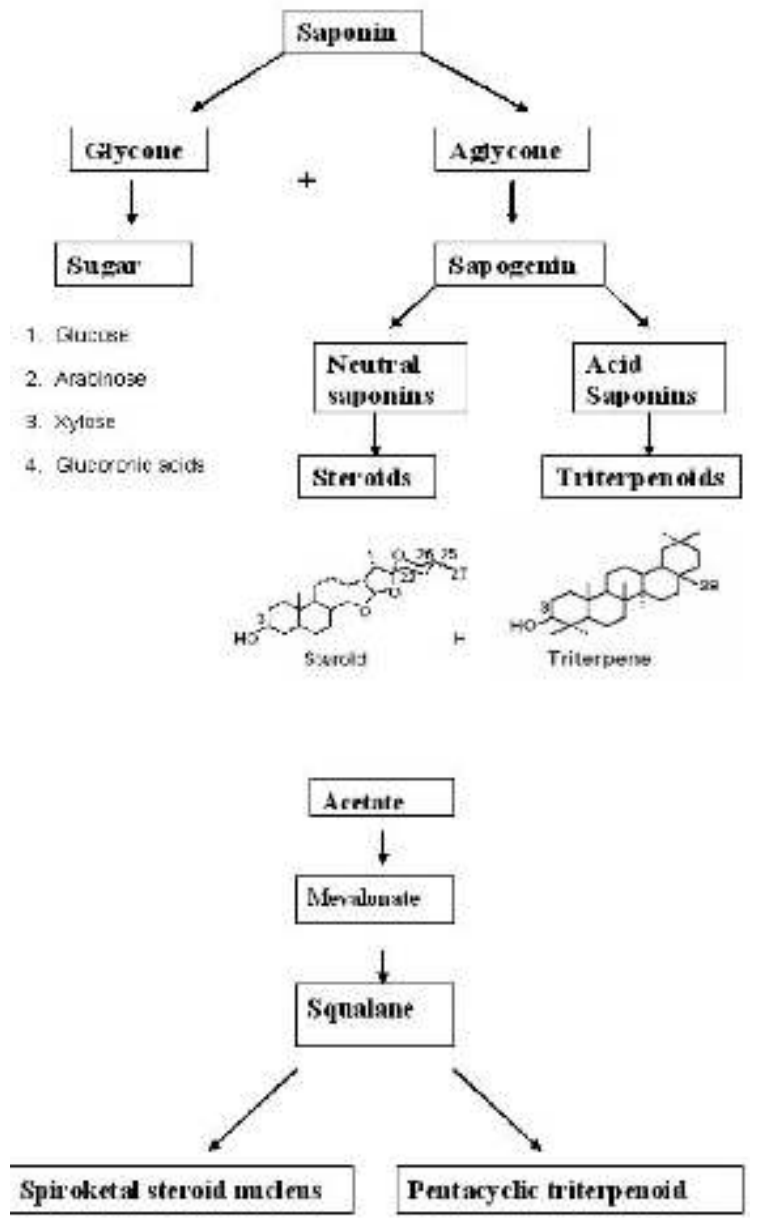

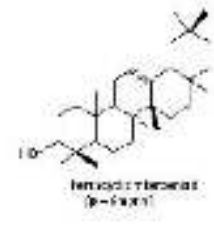

after the formation of the triterpenoid hydrocarbon, squalene, that leads to steroids in one direction and to cyclic triterpenoids in the other.

\section{Biological role in animal systems}

Effects on cell membranes: A large number of the biological effects of saponins have been ascribed to their action on membranes. In fact, their specific ability to form pores in membranes has contributed to their common use in physiological research. Saponins have long been known to have a lytic action on

erythrocyte membranes and this property has been used for their detection. The haemolytic action of saponins is believed to be the result of the affinity of the aglycone moiety for membrane sterols, particularly cholesterol with which they form insoluble complexes. The lesions that are caused by saponins are thought to be a micelle-like aggregation of saponins and cholesterol in the plane of the membrane, possibly with saponin molecules arranged in a ring with their hydrophobic moieties combined with cholesterol around the outer perimeter. The membrane pores or defects produced by saponins were long lasting and such membranes were then permanently permeable to large molecules like ferritin (Seeman, 1974). Besides, soyasaponins I and III, and dehydrosoyasaponin I have been shown to be able to open large $\mathrm{Ca}$-dependent $\mathrm{K}$ conductance channels causing membrane hyperpolarization, suppression of electrical activity and relaxation of smooth muscle (McManus et al., 1993).

Effects on nutrient uptake through the intestinal membrane: Dietary saponins are poorly absorbed, so their biological effects occur in the digestive tract (Cheeke, 1996). Johnson et al., (1986) found that some saponins increase the permeability of intestinal mucosal cells in vitro, and inhibit active mucosal transport and facilitate uptake of substances that are normally not absorbed. Saponins (from Gypsophila, Quillaja, clover, guar and lucerne) also reduces transmural potential difference (TPD, the electrochemical gradient that acts as a driving force for active nutrient transport across the brush border membrane of the intestine) across the small intestine of the rat (Gee et al., 1989). An increase in the apparent permea-bility of the brush border observed at sublethal levels of saponins may have important implications for the uptake of macromolecules, such as allergens, whose passage through the epithelium is normally somewhat restricted (Gee et al., 1996). The presence of Gypsophila saponins enhanced the uptake of $\beta$ lactoglobulin, a milk allergen in the jejunal loops' tips of brown Norway rats (Gee et al., 1997).

Some reports describe obstruction of the absorption of micronutrients by dietary saponins. Like, Gypsophila saponins in the diet depressed mean liver iron $(\mathrm{Fe})$ concentrations and total liver $\mathrm{Fe}$ by impairing $\mathrm{Fe}$ absorption (Southon et al., 1988). Probably the saponin formed complexes with dietary Fe rendering it unavailable for absorption. Lucerne saponins were shown to increase excretion of $\mathrm{Fe}$ and magnesium $(\mathrm{Mg})$ when present in rat diets, and reduce plasma calcium $(\mathrm{Ca})$ and zinc (Zn) in pigs (Southon et al., 1988). These saponins could complex with $\mathrm{Fe}$ and $\mathrm{Zn}$ in vitro and 
this complex formation might have hindered their absorption. Triterpenoid saponins from Gypsophila and Quillaja included in the diet appeared to interfere with the absorption of vitamins $\mathrm{A}$ and $\mathrm{E}$ in chicks (Jenkins and Atwal, 1994). But feeding a steroid saponin (sarsasaponin) at the same level had no effect on any of these parameters.

Effects in other single-stomached animals: There are also numerous reports of negative effects of dietary saponins. Dietary saponins depressed growth, feed consumption and egg production in poultry (Jenkins and Atwal, 1994). These negative effects have been ascribed to several properties of saponins such as reduced feed intake caused by the astringent and irritating taste of saponins (Oleszek et al., 1994), reduction in intestinal motility (Klita et al., 1996), reduction in protein digestibility (Shimoyamada et al., 1998) and damage to the intestinal membrane and inhibition of nutrient transport described earlier in the present review.

Effects on protein digestion: Saponins reduce protein digestibility by the formation of sparingly digestible saponin-protein complexes (Potter et al., 1993). Endogenous saponins affected the chymotrypsic hydrolysis of soyabean protein, particularly glycinin (Shimoyamada et al., 1998). The digestibility of the bovine serum albumin-soyasaponin complex was much lower than that of free bovine serum albumin indicating that complexing with saponin had an obstructing effect.

\section{Effect on rumen environment}

Rumen fermentation: Jouany (1996) reported that ciliate protozoa contributed significantly to intraruminal cycling of microbial nitrogen $(\mathrm{N})$ and efficiency of microbial crude protein (MCP) synthesis, so reducing protozoa counts can improve dietary $\mathrm{N}$ utilization and increase MCP flow to the intestine. Total concentrations of volatile fatty acids (VFA) were reduced by elimination of protozoa. In the defaunated rumen fluid, molar proportion of propionate was increased at the apparent expense of butyrate. Because protozoa in the rumen cause protein turnover by predating on bacteria, defaunation increases the nitrogen utilization of the ruminant and may lead to an increase in growth, milk, or wool production (Wina et al., 2005).

Yucca extract can also bind $\mathrm{NH}_{4}$ when ruminal $\mathrm{NH}_{4}$ concentrations are high, and release it again when ruminal $\mathrm{NH}_{4}$ is low, providing a continuous and adequate supply of $\mathrm{NH} 4$ for microbial protein synthesis (Hussain and Cheeke, 1995). A positive effect of
Yucca saponins in ruminant nutrition was attributed to the enhancement of the entrapment of $\mathrm{NH}_{4}-\mathrm{N}$ from urea-supplemented straw (Makkar et al., 1999). This increases the availability of nutrients to rumen bacteria and reduces environmental damage by decreasing losses of $\mathrm{NH}_{4}$ to the air.

The saponins of lucerne origin had a detrimental effect on rumen fermentation and caused a reduction in total VFA and acetate to propionate ratio from 1.93 to 1.37 in the presence of $1 \%$ saponin in the medium. The rumen microbes are able to deglycosylate the saponins to release the steroid moiety, which affects rumen fermentation. Yucca schidigera extract has been found to alter rumen fermentation favourably, increase animal growth and milk production. Thalib et al., (1996) studied the effect of saponins of Sapindus rarak fruit on rumen microbes of sheep and reported that the methanol extract of seeds caused a $57 \%$ reduction in the number of protozoa and $69 \%$ increase in bacterial population which resulted in improved feed conversion efficiency and better gain in body weight of the animals. Dietary saponins were often suspected of having a role in causing ruminant bloat (Cheeke, 1996; Sen et al., 1998), but clear experimental proof for this is lacking in the literature. The absence of any positive effect in experiments where Yucca saponins were fed to ruminants (Wu et al., 1994) might have been because animals with adapted rumen microbial population were used.

Effect on Defaunation: There has been increased interest in saponin containing plants as a possible means of suppressing or eliminating protozoa in the rumen. Saponins react with cholesterol in the protozoal cell membrane, causing the cell to rupture and lyse (Wina et al., 2005). In ruminants saponins are differentially toxic to rumen protozoa. The differential toxicity may be explained by the presence of cholesterol in eukaryotic membranes but not in prokaryotic cells (Kilta et al., 1996). Saponins are degraded in batch cultures of rumen fluid in vitro (Makkar and Becker, 1997), although apparently the resultant sapogenins are more resistant to degradation (Wang et al., 1998). Sapogenins do not have the anti-protozoal property of the parent saponin (Teferdegne et al., 1998). Foliage from Sesbania sesban, a multi-purpose leguminous tree from sub-Saharan Africa, inhibited protozoal activity in vitro and transiently depressed the number of protozoa in the rumen of sheep in the United Kingdom (Newbold et al., 1997; Teferedegne et al., 1999). Goel et al., (2008a) reported $47.9 \%$ decrease in protozoal number in vitro studies with saponin extracted from $S$. sesban leaves and dosage was 
$174 \mathrm{~g} / \mathrm{kg}$ hay. In contrast, feeding trial carried out in Ethiopia failed to find any effect on protozoal numbers in the rumen of sheep fed on S. sesban (Odenyo et al., 1997; Teferedegne et al., 1999). However, when $S$. sesban was placed directly into the rumen via a rumen cannula, protozoal numbers decreased significantly (Odenyo et al., 1997). This finding suggests that deactivation of the saponins may have occurred before reaching the rumen, probably in the mouth by saliva.

Effect on Rumen Bacteria: Newbold et al., (1997) have found that bacterial numbers increase when foliage from $S$. sesban is introduced into the diet, presumably as a consequence of the suppression of protozoal numbers. Valdez et al., (1986) have found a similar trend with $Y$. schidigera extract. Steroidal saponins from $Y$. schidigera have no effect on total or cellulolytic bacterial counts in Rusitec, however, inoculating fluid from the fermenter into a medium containing saponins decreases the viable count (Wang et al., 1998).

Experiments using pure cultures of rumen bacteria have indicated that there are also possible antibacterial effects of saponins. $Y$. schidigera extract abolishes growth of the fibre digester, Butyrivibrio fibrisolvens, and prolongs the lag phase of Streptococcus bovis (Wallace et al., 1994). Similar sensitivity of $S$. bovis to $Y$. schidigera extract has been found by Wang et al., (2000), who additionally found that cellulose digestion by Ruminococcus spp. and Fibrobacter succinogenes is inhibited.

Effect on Rumen Fungi: A potentially very important observation is that the anaerobic rumen fungi, Neocallimastix frontalis and Piromyces rhizinflata, are highly sensitive to $Y$. schidigera saponins (Wang et al., 2000). Rumen fungi appear to fill an important niche in the digestion of recalcitrant plant fibres, because they cause physical as well as enzymic disruption of plant cell walls (Orpin and Joblin, 1997). Thus, it may well be advantageous to promote the bacterial detoxification of the saponins in animals receiving poor-quality forages or crop by-products.

Effects on cholesterol metabolism: A number of studies have shown that saponins from different sources lower serum cholesterol levels in a variety of animals including human subjects. Large mixed micelles formed by the interaction of saponins with bile acids account for their increased excretion when saponin-rich foods such as soyabean, lucerne and chickpea are consumed (Oakenfull and Sidhu, 1990). As the saponin decreases absorption of both endogenous and exogenous chlolesterol and thereby, accelerated the metabolism of cholesterol in the liver resulting lower serum levels. Saponins also reduced the more harmful LDL-cholesterol selectively in the serum of rats, gerbils and human (Matsuura, 2001). Other suggested mechanisms of action of saponins include delaying the intestinal absorption of dietary fat by inhibiting pancreatic lipase activity (Han et al. 2000).

Effects on the immune system: Saponin based adjuvants have the unique ability to stimulate the cellmediated immune system, as well as to enhance antibody production and have the advantage that only a low dose is needed for adjuvant activity (Oda et al., 2000). The mechanisms of immune-stimulating action of saponins have not been clearly understood, but many explanations have been put forward. Saponins reportedly induced production of cytokines such as interleukins and interferons that might mediate their immunostimulant effects (Kensil, 1996). There is evidence that saponins may increase the immune response by increasing the uptake of antigens from the gut and other membranes.

Effect on methanogenesis: Many researches had been carried out to find ways to lower the methane production in ruminant animals. The symbiosis of protozoa with methanogenic archaea was described by Finlay et al., (1994) and selective suppression of the rumen protozoa had been suggested to be a promising approach to reduce methane release (Dohme et al., 1999; Moss et al., 2000). Inclusion of saponin significantly reduced methane production in faunated rumen fluid, but not in the defaunated rumen fluid, suggesting that inhibition of methanogenesis by tea saponins was primarily due to their anti-protozoal activity. Formation of acetate and butyrate are usually accompanied by production of hydrogen and carbon dioxide, whereas propionate formation involves a net uptake of hydrogen, thus, defaunation decreases the hydrogen supply for methanogens in the rumen, leading to lower methane emission. Anumber of studies have reported that saponins or plants rich in saponins decreased the methane production in the rumen both in vitro (Pen et al., 2006, 2008; Holtshausen et al., 2009) and in vivo (Pen et al., 2007; Santoso et al., 2004; Wang et al., 2009a; Holtshausen et al., 2009) studies. Additionally, it has been suggested that methane production may also be affected by saponins as a result of reduced rate of methanogenesis via diminished activity of methane producing gene without changing the total methanogen population (Guo et al., 2008).

As a Haemolytic agent: The saponins cause 
haemolysis of red blood cells perhaps by increasing the permeability of the plasma membrane and inhibit smooth muscle activity. Baumann et al., (2000) investigated the effect of saponins on the membrane structure through haemolysis of human erythrocytes. The findings showed that saponin-lysed erythrocytes do not reseal, and therefore indicates that saponin damage to the lipid bilayer is irreversible.

Microbial adaptation and degradation of saponins: One of the problems encountered in the use of saponin containing plants is that there appears to be adaptation of the mixed microbial population of the rumen to saponins or saponin-containing plants. The first indication has come from comparative studies between sheep in Ethiopia and sheep in the UK. Foliage from S. sesban inhibits protozoal activity in vitro in rumen fluid taken from sheep in the UK; similar inhibition does not occur in rumen fluid from Ethiopian sheep (Teferedegne et al., 1999). Protozoa that have been washed substantially free of bacteria respond in the same way in both places, thus, it appears that the bacterial population detoxifies $S$. sesban in the Ethiopian sheep but not the British sheep. It has been speculated that the Ethiopian sheep had probably been exposed to saponin rich forage whereas the British sheep had not. The effectiveness of S. sesban in suppressing protozoa has been shown to be only transient in the UK sheep, presumably for the same reason (Newbold et al., 1997). A puzzling observation made by Odenyo et al., (1997) is that S. sesban introduced directly into the rumen remains toxic to protozoa, but dietary $S$. sesban is ineffective. This result implies either that chewing causes detoxification, perhaps by salivary amylase or that the larger particle size protects saponins from degradation.

\section{Commercial use}

The two major commercial sources of saponins are Yucca schidigera, which grows in the arid Mexican desert country of Baja California, and Quillaja saponaria (soapbark tree), found in arid areas of Chile. Due to the surface-active properties, saponins are excellent foaming agents, forming very stable foams. Yucca extracts are extensively used for ammonia and odor control in pig and poultry-raising facilities and in dog and cat foods. Yucca saponins, and perhaps other components of Yucca as well, have ammonia-binding activity. When added to the diet, Yucca saponins pass through the digestive tract unabsorbed and are excreted in the feces. In the excreta, the Yucca components bind to ammonia and prevent them from being released into the air.

\section{I solation of saponins}

Plant saponins are isolated in the following ways;

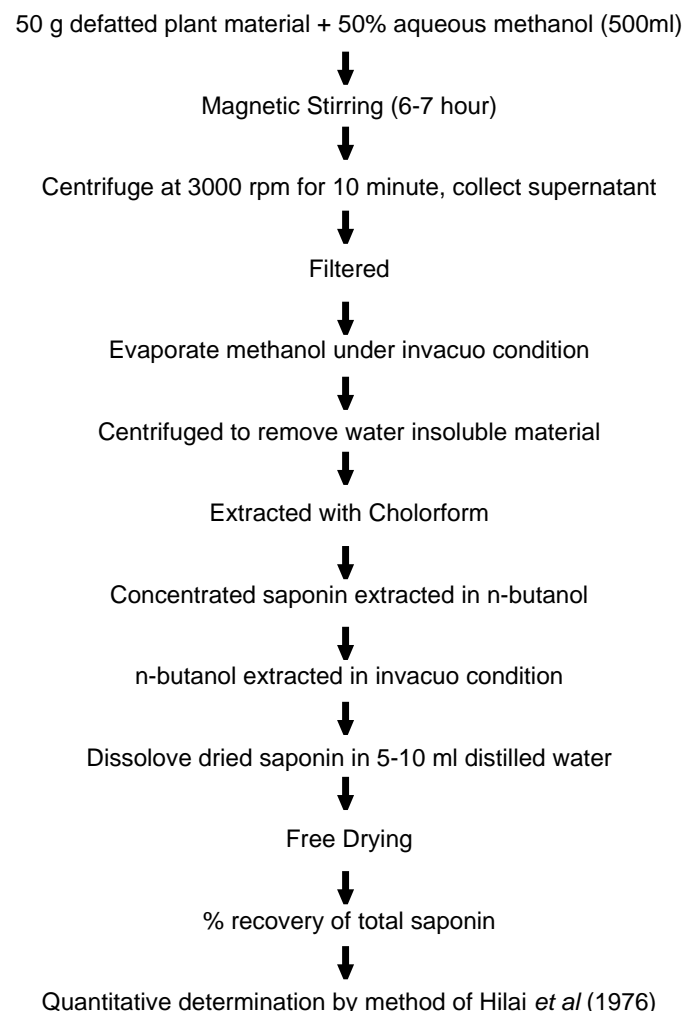

\section{References}

1. Baumann, E., Stoya, G., Völkner, A., Richter, W., Lemke, C. and Linss, W. (2000). Hemolysis of human erythrocytes with saponin affects the membrane structure. Acta Histochemica. 102: 21-35.

2. Cheeke, P.R. (1996). Biological effects of feed and forage saponins and their impact on animal production. In Saponins Used in Food and Agriculture, pp. 377-386 [GR Waller and Y Yamasaki, editors]. New York: Plenum Press.

3. Dohme, F., Machmuller, A., Estermann, B.L., Pfister, P., Wasserfallen, A. and Kreuzer, M. (1999). The role of the rumen ciliate protozoa for methane suppression caused by coconut oil. Letters Applied Microbial.29:187-192.

4. Finlay, B.J., Esteban, G., Clarke, K.J., Williams, A.G. Embley, T.M. and Hirt, R.P. (1994). Some rumen ciliates have endosymbiotic methanogens. FEMS Microbiology Letters. 117:157-162.

5. Freeland, W.J., Calcott, P.H. and Anderson, L.R. (1985). Tannins and saponins: Interaction in herbivore diets. Biochem Systematic Ecol. 13: 189-193.

6. Gee, J.M., Price, K.R., Ridout, C.L., Johnson, I.T. 
and Fenwick, G.R. (1989). Effects of some purified saponins on transmural potential difference in mammalian small intestine. Toxicol. 3: 85-90.

7. Gee, J.M., Wortley, G.M., Johnson, I.T., Price, K.R. Rutten, A.A.J.J.L., Houben, G.F. and Penninks, A.H (1996). Effect of saponins and glycoalkaloids on the permeability and viability of mammalian intestinal cells and on the integrity of tissue preparations in vitro. Toxicol. 10: 117-128.

8. Gee, J.M., Wal, J.M., Miller, K., Atkinson, H., Grigoriadou, F., Wijnands, M.V.W., Penninks, A.H., Wortley, G. and Johnson, I.T. (1997). Effect of saponin on the transmucosal passage of $\beta$ lactoglobulin across the proximal small intestine of normal and b-lacoglobulin-sensitised rats. Toxicol. 117: 219-228.

9. Goel, G., Makkar, H.P.S. and Becker, K. (2008).Effect of Sesbania sesban and Carduus pycnocephalus leaves and fenugreek (Trigonella foenum-graecum $L$.) seeds and their extracts on partitioning of nutrient from roughage and concentrate based feeds to methane. Anim Feed Sci and Technol. 147: 72-89.

10. Guo, Y.Q., Liu, J.-X., Lu, Y., Zhu, W.Y., Denman, S.E. and McSweeney, C.S. (2008). Effect of tea saponin on methanogenesis, microbial community structure and expression of mcrA gene, in cultures of rumen microorganisms. Lett. Appl. Microbiol.47: 421-426.

11. Han, L.K., Xu, B.J., Kimura, Y., Zheng, Y.N. and Okuda, H. (2000). Platycodiradix affects lipid metabolism in mice with high fat dietinduced obesity. J Nutr. 130:2760-2764.

12. Hiai, S., Oura, H. and Nakajima, T. (1976). Color reaction of some sapogenins and saponins with vanillin sulfuric acid. Planta Med.29: 116-122.

13. Holtshausen, L., Chaves, A.V., Beauchemin, K.A., McGinn, S.M., McAllister, T.A., Odongo, N.E., Cheeke, P.R. and Benchaar, C. (2009). Feeding saponin-containing Yucca schidigera and Quillaja saponaria to decrease enteric methane production in dairy cows. J Dairy Sci. 92: 2809-2821.

14. Hostettmann, K. and Marston, A. (1995). Saponins. Cambridge: Cambridge University Press.

15. Hussain, I. and Cheeke, P.R. (1995). Effect of Yucca scidigera extract on rumen and blood profiles of steers fed concentrate- or roughage- based diets. Anim Feed Sci Technol.51:231-242.

16. Jenkins, K.J. and Atwal, A.S. (1994). Effects of dietary saponins on fecal bile acids and neutral sterols, and availability of vitamins $\mathrm{A}$ and $\mathrm{E}$ in the chick. $J$ Nutri Biochem. 5:134-138

17. Johnson, I.T., Gee, J.M., Price, K., Curl, C. and Fenwick, G.R. (1986). Influence of saponins on gut permeability and active nutrient transport in vitro. $J$ Nutri. 116: 2270-2277.

18. Jouany, J.P. (1996). Effect of rumen protozoa on nitrogen utilization by ruminants. J Nutri. 126:13351346.

19. Kensil, C.R. (1996). Saponins as vaccine adjuvants.
Critical Reviews in Therapeutic Drug Carrier Systems. 13: 1-55.

20. Kilta, P.T., Mathison, G.W. and Fenton, T.W. (1996). Effect of alfalfa root saponins on digestive function in sheep. J Anim Sci.74: 1144-1156.

21. Makkar, H.P. and Becker, K. (1997). Degradation of Quillaja saponins by mixed culture of rumen microbes. Letters Applied Microbiol, 25: 243-245.

22. Makkar, H.P.S., Aregheore, E.M. and Becker, K. (1999). Effects of saponins and plant extracts containing saponins on the recovery of ammonia during urea ammoniation of wheat straw and fermentation kinetics of the treated straw. J Agri Sci. 132: 313-321.

23. Matsuura, M. (2001). Saponins in garlic as modifiers of the risk of cardiovascular disease. J Nutri. 131:1000S-1005S.

24. McManus, O.B., Harris, G.H. and Giangiacombo, K.M. (1993). An activator of calcium-dependen potassium channels isolated from a medicinal herb. Biochemistry. 32:6128-6133.

25. Moss, A.R., Jouany, J.P. and Newbold, J. (2000) Methane production by ruminants: Its contribution to global warming. Annal Zootechnol. 49:231-253.

26. Newbold, C.J., El Hassan, S.M., Wang, J., Ortega, M.E. and Wallace, R.J. (1997). Influence of foliage from African multipurpose trees on activity of rumen protozoa and bacteria. Br J Nutr. 78: 237-249.

27. Oakenfull, D.G. and Sidhu, G.S. (1990). Could saponins be a useful treatment for hypercholesterolemia? European J Clinical Nutri. 44: 79-88.

28. Oda, K., Matsuda, H., Murakami, T., Katayama, S., Ohgitani, T. and Yoshikawa, M. (2000). Adjuvant and haemolytic activities of saponins derived from medicinal and food plants. Biol Chemistry. 381: 6774

29. Odenyo, A.A., Osuji, P.O. and Karanfil, O. (1997) Effect of multipurpose tree (MPT) supplements on ruminal ciliate protozoa. Anim Feed Sci Technol. 67: $169-180$

30. Oleszek. W/, Nowacka. J., Gee, J.M., Wortley, G. and Johnson, I.T. (1994). Effects of some purified alfalfa (Medicago sativa) saponins on transmural potential difference in mammalian small intestine. $J$ Sci Food Agri. 65: 35-39.

31. Orpin, C.G and Joblin, K.N. (1997). The rumen anaerobic fungi. In: The Rumen Microbial Ecosystem, pp. 140-195 [PN Hobson and CS Stewart, editors]. London: Chapman and Hall.

32. Pen, B., Sar, C., Mwenya, B., Kuwaki, K., Morikawa, R. and Takahashi, J. (2006). Effects of Yucca schidigera and Quillaja saponaria extracts on in vitro ruminal fermentation and methane emission. Anim. Feed Sci. Technol. 129: 175-186.

33. Pen, B., Takaura, K., Yamaguchi, S., Asa, R. and Takahashi, J. (2007). Effects of Yucca schidigera and Quillaja saponaria with or without b-1, 4 galacto-oligosaccharides on ruminal fermentation, methane 
production and nitrogen utilization in sheep. Anim.Feed Sci. Technol. 138: 75-88.

34. Pen, B., Sar, C., Mwenya, B. And Takahashi, J. (2008). Effects of Quillaja saponaria extract alone or in combination with Yucca schidigera extract on ruminal fermentation and methanogenesis in vitro. Anim. Sci. J. 79: 193-199.

35. Potter, S.M., Jimenez-Flores, R., Pollack, J., Lone, T.A. and Berber-Jimenez, M.D. (1993). Protein saponin interaction and its influence on blood lipids. $J$ Agri Food Chem. 41: 1287-1291.

36. Santoso, B., Mwenya, B., Sar, C., Gamo, Y., Kobayashi, T., Morikawa, R., Kimura, K., Mizukoshi, H. and Takahashi, J. (2004). Effects of supplementing galactooligosaccharides, Yucca schidigera and nisin on rumen methanogenesis, nitrogen and energy metabolism in sheep. Livest. Prod. Sci. 91: 209-217.

37. Seeman, P. (1974). Ultrastructure of membrane lesions in immune lysis, osmotic lysis and druginduced lysis. Federation Proc. 33: 2116-2124.

38. Sen, S., Makkar, H.P.S. and Becker, K. (1998). Alfalfa saponins and their implication in animal nutrition. $J$ Agri Food Chem. 46: 131-140.

39. Shimoyamada, M., Ikedo, S., Ootsubo, R. and Watanabe, K. (1998). Effects of soybean saponins on chymotryptic hydrolyses of soybean proteins. J Agri Food Chem. 46: 4793-4797.

40. Southon, S., Johnson, I.T., Gee, J.M. and Price, K.R. (1988). The effect of Gypsophylla saponins in the diet on mineral status and plasma cholesterol concentration in the rat. BrJ Nutr. 59: 49-55.

41. Teferedegne, B., Osuji, P.O., Odenyo, A., Wallace, R.J. and Newbold, C.J. (1998). Influence of saponins/sapogenins on the bacteriolytic activity of ciliate protozoa from the sheep rumen. Proc $\mathrm{Br}$ SocietyAnim Sci. 122Abstr.

42. Teferedegne, B., McIntosh, F., Osuji, P.O., Odenyo, A., Wallace, R.J. and Newbold, C.J. (1999). Influence of foliage from different accessions of the sub-tropical leguminous tree, Sesbania sesban, on ruminal protozoa in Ethiopia and Scottish sheep. Anim Feed SciTech.78 (1-2): 11-20.
43. Thalib, A., Y. Widiawati, H. Hamid, D. Suherman and M. Sabrani. (1996). The effects of saponin from Sapindus rarak fruit on rumen microbes and performance of sheep. J. Ilmu Ternak Vet. 2:17-20.

44. Valdez, F.R., Bush, L.J., Goetsch, A.L. and Owens. F.N. (1986). Effect of steroidal sapogenins on ruminal fermentation and on production of lactating dairy cows. J Dairy Sci. 69: 1568-1575.

45. Vincken, J.-P., Heng, L., De Groot, A. and Gruppen, H. (2007). Saponins, classification and occurrence in the plant kingdom. Phytochem. 68: 275-297.

46. Wallace, R.J., Arthaud, L. and Newbold, C.J. (1994). Influence of Yucca shidigera extract on ruminal ammonia concentrations and ruminal micro-organisms. Applied Environ Microbiol. 60:1762-1767.

47. Wang, Y., McAllister, T.A., Newbold, C.J., Rode, L.M., Cheeke, P.R. and Cheng, K.J. (1998). Effects of Yucca schidigera extract on fermentation and degradation of steroidal saponins in the rumen simulation technique (RUSITEC). Anim Feed Sci Tech. 74: 143-153.

48. Wang, Y., McAllister, T.A., Yanke, L.J. and Cheeke, P.R. (2000). Effect of steroidal saponin from Yucca schidigera extract on ruminal microbes. J Applied Microbiol. 88: 887-896.

49. Wang, C.J., Wang, S.P. and Zhou, H. (2009). Influences of flavomycin, ropadiar, and saponin on nutrient digestibility, rumen fermentation, and methane emission from sheep. Anim. Feed Sci. Technol. 148: 157-166.

50. Wina, E., Muetzel, S. and Becker, K. (2005). The impact of saponins or saponin containing plant materials on ruminant production - A Review. J Agri Food Chem. 53:8093-8105.

51. Wu, Z., Sadik, M. and Sleiman, F.T. (1994). Influence of Yucca extract on ruminal metabolism in cows. $J$ Animal Sci.72:1038-1042.

52. Yoshiki, Y., Kudou, S. and Okubo, K. (1998). Relationship between chemical structures and biological activities of triterpenoid saponins from soybean (Review). Biosci Biotech Biochem. 62: 2291-2299. 